\title{
Endoscopic Appearance of Primary Anorectal Melanoma
}

Anorectal melanoma is an uncommon tumor that has a poor prognosis. The sigmoidoscopic appearance helps to distinguish this condition from more common anorectal disorders, such as adenocarcinomas and hemorrhoids. Endoscopic diagnosis of anorectal melanoma has occasionally been reported (1).

We report here a case of primary anorectal melanoma seen in a $65-$ year-old woman. She presented with complaints of bloody stools, constipation, and weight loss that had continued for two months. A large, hard, and painless mass was felt posteriorly on a digital rectal examination. Proctoscopy and sigmoidoscopy revealed a mainly black, friable, ulcerated mass, measuring approximately $4 \mathrm{~cm}$ and located about $3 \mathrm{~cm}$ from the anal verge (Figure 1). Abdominal ultrasonography showed multiple cavitating metastases in the liver. Computed tomography of the pelvis showed a mass arising from the posterior and lateral wall of the rectum and measuring approximately $4.5 \times 3.5 \times 2.5 \mathrm{~cm}$. The mass was confined to the rectum, with no involvement of surrounding structures. Biopsies of the mass revealed multiple spindle-shaped cells interspersed with polygonal cells, with atypia, containing a brownish-black pigment and prominent nucleoli (Figure 2). Biopsy confirmed a malignant melanoma of the anorectum.

Anorectal melanomas account for only $0.4-1.6 \%$ of primary malignant melanomas (2). The overall five-year survival rate is approximately $13 \%$. Black pigmentation in a nodule, with ulceration and friability, are common endoscopic findings; however, one-third of melanomas are amelanotic (3). In the present case, the diagnosis was based on the sigmoidoscopic findings and biopsy of the mass. The presence of liver metastases and the patient's poor general health precluded surgical removal of the tumor.

R. Gupta, P. M. Rathi, P. Sawant, C. P. Shroff, A. P. Upadhyay, M. S. Bhatnagar

Dept. of Gastroenterology, Dept. of Pathology, L.T.M. Medical College and L.T.M. General Hospital, (Bombay) India

\section{References}

1. Rubin KP, Ghanekar D, Friedrich A, Panella VS. Endoscopic diagnosis of anorectal melanoma. N J Med 1992; 89: 309-10.

2. Ross M, Pezzi C, Pezzi T, et al. Patterns of failure in anorectal melanoma. Arch Surg 1990; 125: 313-16.

3. Weinstock MA. Epidemiology and prognosis of anorectal melanoma. Gastroenterology 1993; 104: 174-8.

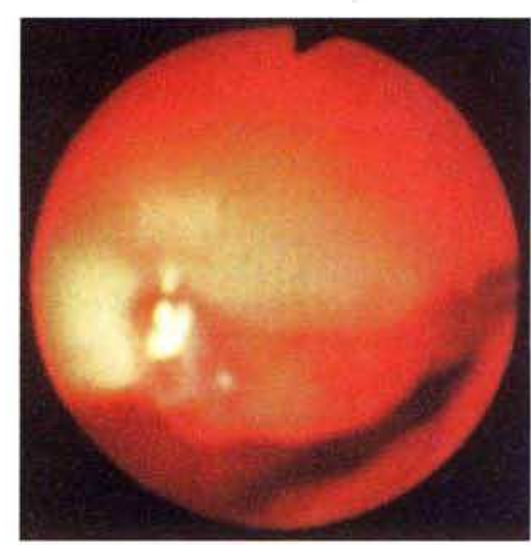

Figure 1: Endoscopic view of the malignant melanom Black pigmentation seen in a mass arisin from the rectum.

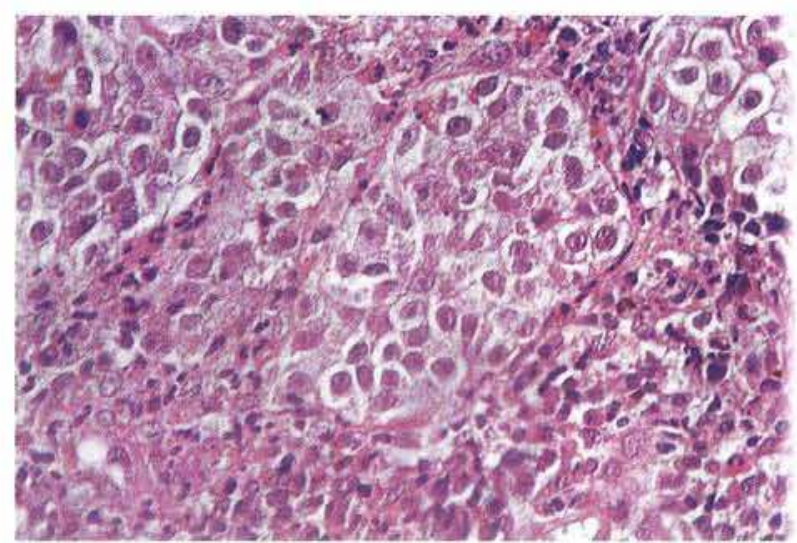

Figure 2: The histological appearance of the tumor biopsy, indicatin malignant melanoma.

Corresponding Author

P. Rathi, M.D.

Dept. of Gastroenterology

L.T.M. Medical College and

L.T.M. General Hospital

Sion

Mumbai (Bombay) 400022

India

Fax: +91-22-407-61 00 